тета. Психолого-педагогические науки. 2012. № 3 (20). C. 94-99.

16. Прочуханова Ю.В., Рябова В.В., Санжапова И.Р. и др. Молодежный социальный проект «Экологический экспресс»// Наука и образование транспорту. 2013. T. 1, № 1. С. 264-266.

17. Добина К.С., Сальникова А.М., Холопов Ю.А. Молодежный социальный проект «Селективный сбор отходов в СамГУПС»// Наука и образование транспорту. 2016. № 2. С. 119-122.

18. Айгубов Л.С., Хаджиалиев К.И. Волонтерская деятельность как средство формирования социальноэкологической культуры студента // Юг России: экология, развитие. 2016. Т. 11, № 4 (41). С. 175-182.

19. Насибов Р.Э., Мехоношин С.А., Холопов Ю.А. Экологическое образование в СамГУПС: Знаем, умеем, действуем! // Экологические, экономические, социальные и правовые аспекты устойчивого развития: тез. докладов междунар. студенческой науч.-практ. конф. Екатеринбург, 2016. С. 52-54.

20. Степанова Е.С. Особенности использования практико-ориентированного подхода в вузе // Мо-

дернизация естественнонаучного образования: методика преподавания и практическое применение: сборник статей V международной научно-практической конференции, посвящённой 120-летию со дня рождения завкафедрой химии, декана естественногеографического факультета Г.М. Мазанко. 2015. C. 104-108.

21. Казанцев И.В., Молчатский С.Л. Научно-исследовательская деятельность студентов как фактор личностного самоопределения // Поволжский педагогический вестник. 2016. № 2 (11). С. 76-81.

22. Холопов Ю.А. Роль вводного занятия при изучении курса экологии // Повышение качества подготовки специалистов для железнодорожного транспорта: мат-лы межвуз. науч.-метод. конф. 2000. C. $42-44$.

23. Холопов Ю.А. Экологическая составляющая подготовки специалистов как залог прогрессивного и устойчивого развития общества // Окружающая среда для нас и будущих поколений: тр. XII междунар. конф. 2007. С. 162-163.

\title{
TECHNICAL UNIVERSITIES STUDENTS' READINESS FOR ECO-ORIENTED VALUES DEVELOPMENT
}

(C) 2017

\author{
Kholopov Yurii Aleksandrovich, candidate of agricultural sciences, \\ associate professor of Construction Department
}

Slugina Anastasiya Nicolaevna, student of Railway Construction and Information Technologies Faculty Stikhanova Svetlana Alexeevna, student of Railway Construction and Information Technologies Faculty Samara State Transport University (Samara, Russian Federation)

Abstract. The article discusses issues related to assessment of readiness of students of a technical College to form the foundations of ecological culture. Emphasized that the problems of modern society due to the long dominance of an anthropocentric attitude towards nature. Increasing anthropogenic pressures are often based on artificial heating of consumer demand. It is shown that the formation of eco-friendly values is impossible only through the educational process. The data of sociological survey of 183 students of the Samara state (133 boys and 50 girls) aged 17 to 22 years, who have not studied ecology. The impact of students on the environment assessed according to the method of the «ecological footprint» proposed by William Reese in 1992: in terms of consumption and way of life, only $16 \%$ of girls and $20 \%$ of boys fit into one planet. It is marked that a key moment in the formation of environmental culture is the choice of information sources. Revealed the following patterns of circulation the youth audience with information that the students prefer as information sources, television and online media, but trust more tutorials $-84 \%$ of girls and $70 \%$ boys; in the modern media for environmental information is presented in a minimal volume that shows the development potential of this mechanism of formation of ecological culture. Girls interested in the environmental, food safety, housing; tackling environmental issues at the level of educational institutions; environmental problems and their solutions in the region of residence. Men prioritize the following topics: activities of public ecological organizations and movements; scientific achievements in the field of ecology; global environmental issues. Only 50\% of girls and $37 \%$ of boys consider themselves to be environmentally educated.

Keywords: ecological footprint; ecological information; ecological culture; sociological survey; mass media; ecological consciousness development; environmental activities; environmental problems; level of consumption.

УДК $371: 17.023$

\section{РАЗВИТИЕ ЛИЧНОСТНЫХ ФОРМ НРАВСТВЕННОГО СОЗНАНИЯ ШКОЛЬНИКА КАК ИДЕЯ ЛИЧНОСТНО ОРИЕНТИРОВАННОГО ОБРАЗОВАНИЯ}

\author{
Цепкова Анжелика Николаевна, кандидат педагогических наук, \\ доцент кафедры социально-гуманитарных и естественнонаучных дисциплин \\ Самарский институт - высшая школа приватизации и предпринимательства \\ (2. Самара, Российская Федераџия)
}

\footnotetext{
Аннотация. В статье обосновывается предположение о том, что одним из способов решения задачи формирования личности школьника, способного к духовно-практическому освоению мира в морали, является реализация учителем личностно ориентированной модели образования. Объясняются причины декларатив-
} 
ности личностно ориентированного образования в современной школе: незыблемость классических устоев традиционной образовательной парадигмы, превращение образования в сферу услуг, неверное понимание педагогами сути личностно ориентированного образования. Раскрывается роль ориентации будущих учителей на реализацию идей личностно ориентированного образования в преодолении причин декларативности личностно ориентированного образования. Рассматривается развитие личностных форм нравственного сознания школьника как идеи личностно ориентированного образования. Доказывается особое значение личностных форм сознания при построении школьником собственных оценочных суждений. Показано, что конкретные личностные формы нравственного сознания учителя могут быть представлены и как личностные формы нравственного сознания школьника. Раскрывается сущность идеи развития личностных форм нравственного сознания школьника, заключающейся в том, что такие личностные формы нравственного сознания, как добро, достоинство, милосердие, ответственность и др., необходимы для построения школьником оценочных суждений, для оценивания, являющегося отправным моментом духовно-практического освоения школьником мира в морали и выявляющего соответствие или несоответствие поступков школьника моральным требованиям.

Ключевые слова: школьник; учитель; будущий учитель; личность; личностно ориентированное образование; идея; личностная форма; нравственное сознание; оценивание; развитие; сущность; духовно-практическое освоение школьником мира в морали; моральное требование.

В контексте смены вектора развития общества одной из задач образования, играющего заметную роль как в формировании ценностных ориентаций школьников, в развитии у них моральной мотивации, так и в преодолении ими бездуховности, безответственности, необразованности, является задача формирования личности школьника, способного к духовно-практическому освоению мира в морали. Одним из возможных способов решения данной задачи является реализация учителем личностно ориентированной модели образования, создающей условия как для полноценного развития личностного опыта и личностных функций субъектов образовательного процесса, так и для организации духовно-практического освоения школьником мира в морали. Однако существует противоречие между стремлением учителя организовывать духовно-практическое освоение школьниками мира в морали и недостаточным осознанием им того, что по такому компоненту образования, как способ освоения школьником мира в морали, знаниевая образовательная модель соответствует положениям регулятивной концепции морали, а личностно ориентированная образовательная модель - положениям концепции духовно-практического освоения мира в морали. Одним из возможных способов разрешения данного противоречия является реализация учителем идей личностно ориентированного образования, в рамках которого осуществляется преимущественно духовно-практическое освоение мира в морали, а школьник, производящий моральные требования и исполняющий их, является субъектом активности в освоении ценностей и норм морали.

Однако анализ образовательной практики показывает, что личностно ориентированное образование во многом остается на уровне декларации. На наш взгляд, этому есть три причины.

Первая причина заключается в том, что в обновленном в результате реформ российском образовании незыблемыми остаются классические устои традиционной образовательной парадигмы. В этом утверждении мы солидарны с А.А. Вербицким и О.Г. Ларионовой, которые перечисляют эти устои. Назовем некоторые из них, по нашему мнению, препятствующие реализации именно личностно ориентированного образования. Это:

- традиционные цели общего и профессионального образования;
- отрыв обучения от воспитания;

- научное знание как главный и единственный источник содержания обучения;

- задачный подход к проектированию содержания обучения;

- канонизированные формы организации учебной деятельности (классно-урочная система);

- доминирование сообщающих, вербальных, монологических методов передачи информации учителем ученику;

- классические критерии оценки контроля качества образования, сводящиеся к измерению уровня усвоения школьниками знаний, умений, навыков, закрепленные законодательно введением ЕГЭ в общеобразовательной школе;

- традиционный консерватизм педагогического сознания учителей, учащихся, родителей, общества в целом, не убежденных в разумности и необходимости навязываемых «сверху» новаций и потому сознательно или неосознанно сопротивляющихся их реализации [1, с. 47-48].

Вторая причина связана с превращением образования в сферу услуг. О.К. Позднякова пишет: «Образование, превращающееся в сферу услуг, направляет свои ресурсы не на развитие нравственности человека, а на формирование успешного человека, ориентированного в первую очередь на пользу, а не на благо» [2, с. 33].

Третья причина связана с пониманием педагогами сути личностно ориентированного образования. В.В. Сериков выделяет наиболее типичные проблемы, связанные с таким пониманием. Это: иллюзия «уже известного», иллюзия «понимания», «этический фетишизм», упрощение теории личностно ориентированного образования [3, с. 170-171].

Поясним, в чем состоит суть данных проблем в понимании В.В. Серикова.

Иллюзия «уже известного» возникает у педагогов тогда, когда, во-первых, само упоминание о личности не вызывает ощущения новизны; во-вторых, о личностно ориентированно образовании педагоги слышат довольно много, однако чаще всего именно слышат, не видя результатов на практике, что приводит к известному разочарованию в возможности создать некое особое образование, ориентированное на развитие личности.

Иллюзия «понимания» обусловлена тем, что педагоги-практики зачастую понимают терминологию 
личностно ориентированного образования в каком-то одном смысле. В то время как различные ученые, занимающиеся личностно ориентированным образованием, вкладывают в употребляемые сходные термины различный смысл.

«Этический фетишизм» при усвоении идей личностно ориентированного образования заключается в том, что, когда речь идет о личностно ориентированном образовании, как правило, употребляются «высокие» слова: личность, гуманность и т.д. Этот «фетишизм» вызывает некоторое отторжение у учителей, которым не вполне ясна стратегия «работы с личностью» в рамках образовательных стандартов, стратифицированности контингента детей и родителей и т.д.

Упрощение теории личностно ориентированного образования состоит в ее приведению к более простым феноменам: к обыденно понимаемому гуманному межличностному взаимодействию учителя и ученика, к индивидуальному и дифференцированному подходам в обучении, к воспитывающему обучению и т.д.

Заметим, что о данных причинах мы уже упоминали в нашей статье, посвященной такой идее личностно ориентированного образования, как развитие личностного опыта ученика [4, с. 29]. Мы полагаем, что одним из способов устранения причин декларативности личностно ориентированного образования является ориентация будущих учителей на реализацию этой идеи.

Обращение к проблеме ориентации будущих учителей на реализацию идеи личностно ориентированного образования вызвано и тем фактом, что в последние годы в отечественном образовании все более устойчивой становится тенденция превращения учащегося из «объекта воздействия» в полноправного партнера педагога по совместной работе, в личность, которая не подлежит каким-либо манипуляциям; воспитание же понимается как процесс совместной жизнедеятельности, как «помощь ребенку в реализации его возможностей» [5, с. 165], где воспитывающий взрослый - посредник между ребенком и миром культуры, миром жизни [6, с. 9]. Поэтому значение приобретает личность педагога, который может стать либо фактором разрушения личности ученика, если подойдет к ней с позиций жесткого управления, манипулирования, либо причиной роста самопонимания, самоуважения, саморазвития личности ребенка. В последнем случае - это учитель, осуществляющий в своей практике верно понимаемое по сути личностно ориентированное образование, позволяющее преодолевать классические устои традиционной образовательной парадигмы.

Проблеме личностно ориентированного образования посвящаются сегодня многие исследования. Прежде всего это работы В.В. Серикова [3; 7-10], И.С. Якиманской [11-13], Е.В. Бондаревской [14], А.А. Плигина $[15 ; 16]$, а также и другие работы (например, статьи М.И. Лукьяновой [17], Т.В. Смолеусовой [18], Г.Ф. Трубиной [19]) и др.

В рамках данной статьи мы остановимся на такой идее личностно ориентированного образования, как развитие личностных форм нравственного сознания школьника.

Для выявления данной идеи важным представляется положение В.В. Серикова о том, что собственно личностным процессом является не усвоение знания как такового, а извлечение из массива информации собственного, личностного знания; не усвоение предложенной извне оценки, а построение собственного оценочного суждения; не выполнение заданной деятельности, а выработка ее индивидуального стиля, способа самовыражения через эту деятельность [3, c. 108].

Осмысление данного положения В.В. Серикова и позволило нам выделить в качестве одной из идей личностного ориентированного образования идею развития личностных форм нравственного сознания школьника. Сделаем в этой связи необходимые пояснения.

При построении собственных оценочных суждений особое значение приобретают личностные формы сознания. В рамках реализации личностно ориентированной образовательной модели оценивание является отправным моментом для духовно-практического освоения школьником мира в морали, для осознания того, является ли он субъектом морального требования с точки зрения производства и исполнения последнего.

Духовно-практическое освоение мира, как пишет А.В. Разин, всегда осуществляется на основе сознания, позволяющего, во-первых, расширить возможности предвосхищения состояний действительности, ее опережающего отражения. Во-вторых, дающего возможность конструировать действительность, которая создается за счет активности сознания [20, c. 378$]$.

По мнению ученого, понятия нравственного сознания служат для выражения различных сторон нравственного отношения, для производства оценок реальности и поступков человека с точки зрения их желательности или, напротив, нежелательности для нормального существования общества и для счастья самого человека [20, с. 427]. В сознании школьника понятия наполняются смыслом, который оказывает влияние и на его моральную мотивацию, являющуюся структурным компонентом нравственного сознания индивида в теории А.И. Титаренко [21, с. 112 113].

В личностных формах (понятиях в терминологии A.В. Разина. - А.Ц.) нравственного сознания, как подчеркивает О.Г. Дробницкий, веления и оценки обращены не равно к любому человеку, а именно к определенному лицу. В этих категориях деятельное лицо представлено не просто как объект оценки и потенциальный исполнитель нравственного долженствования, но и как субъект - автор этого требования к себе [22, с. 59-60].

Осмысление идей О.Г. Дробницкого о личностных формах нравственного сознания показывает, что они в теории ученого о таком сознании являются одной из разновидностей морального требования. В личностных формах сознания выражен не просто чей-то индивидуальный способ представлений, но «особый строй моральных отношений, требований, так сказать, второго порядка, развивающихся на основе общеобязательных нормативов нравственности» $[22$, с. 60$]$. Оценивание, выявляя соответствие или несоответствие поступков школьника моральным требованиям, необходимо для духовно-практического освоения ребенком мира в морали. 
Обратим внимание на тот факт, что, говоря о личностных формах нравственного сознания, мы, вслед за О.Г. Дробницким, употребляем их в моральном, нормативно-оценочном смысле, а не в теоретическом смысле [22, с. 39]. «С этой точки зрения, - пишет О.К. Позднякова, - понятия нравственного сознания выражают нормативные требования и оценки, сочетание которых отражает особенность только нравственного сознания. Они обладают значением моральных ценностей, которые отражают актуальное и потенциальное, сущее и должное» [23, c. 162]. В нравственном сознании учителя, по мнению О.К. Поздняковой, четко выделяется его ценностный «ярус», учет которого служит отправным моментом для наполнения конкретным содержанием личностных форм нравственного сознания, в которых выражен особый строй моральных отношений учителя [23, с. 162]. И добавим - учащегося.

Мы полагаем возможным экстраполировать в рамках нашей работы идеи О.К. Поздняковой о нравственном сознании учителя в том плане, что выделяемые ученым конкретные личностные формы нравственного сознания учителя могут быть представлены и как личностные формы нравственного сознания школьника.

В качестве личностных форм нравственного сознания в значении ценностей О.К. Позднякова выделяет следующие: «добро», «добродетель», «долг», «достоинство», «милосердие», «ответственность», «польза», «свобода», «совесть», «справедливость», «стыд», «счастье», «удовольствие», «честь» [2, с. 24].

С нашей точки зрения, данные личностные формы в той или иной мере находят отражение в разработанных В.В. Сериковым, Е.В. Бондаревской, И.С. Якиманской, А.А. Плигиным положениях о личностно ориентированном образовании.

Так, В.В. Сериков среди качеств, свидетельствующих о наличии у школьника личностного опыта, выделяет ответственность и стремление к свободе [3, с. 162].

Е.В. Бондаревская, рассматривая в качестве цели воспитания человека культуры, ядром личности которого являются субъектные свойства, определяющие меру его свободы, гуманности, духовности, жизнетворчества [14, с. 46], раскрывает данные свойства через систему качеств, которые необходимо воспитывать у школьника, а также через систему характеристик. Развивая мысль о человеке культуры как о свободной личности, ученый акцентирует внимание на таких его характеристиках, как чувство собственного достоинства, умение нести ответственность за свои поступки, умение совершать свободный выбор. У человека культуры как гуманной личности любовь к людям, ко всему живому сочетается с милосердием, добротой. Человеку культуры как духовной личности свойственен поиск смысла жизни, счастья, идеала [14, с. 46-47].

И.С. Якиманская полагает, что личностно ориентированный образовательный процесс не на словах, а на деле обеспечивает условия для становления у ребенка умений принимать самостоятельные и ответственные решения, принимать ответственность за себя и свое окружение [13, с. 23]. Раскрывая содержание принципов разработки личностно ориентированной технологии обучения, ученый пишет, что проектирование работы по использованию в образовательном процессе субъектного опыта ученика предполагает предоставление ученику свободы выбора дидактического материала при усвоении знаний $[13$, с. 17].

Модель личностно ориентированной школы, по мнению А.А. Плигина, отличается от других существующих моделей прежде всего тем, что она предоставляет ребенку большую свободу выбора в процессе обучения $[15$, с. 106], на принципах сотрудничества и свободы выбора, по мнению ученого, строятся и отношения «учитель - ученик».

Итак, сущность идеи развития личностных форм нравственного сознания школьника заключается в том, что данные формы нравственного сознания необходимы для построения школьником оценочных суждений, для оценивания, являющегося отправным моментом для духовно-практического освоения школьником мира в морали и выявляющего соответствие или несоответствие поступков школьника моральным требованиям.

\section{СПИСОК ЛИТЕРАТУРЫ:}

1. Вербицкий А.А., Ларионова О.Г. Личностный и компетентностный подходы в образовании: проблемы интеграции. М.: Логос, 2009. 336 с.

2. Позднякова О.К. Формирование нравственного сознания будущего учителя в процессе обучения в педагогическом университете: дис. ... д-ра пед. наук: 13.00.01. Самара, 2006. 492 с.

3. Сериков В.В. Обучение как вид педагогической деятельности. М.: Академия, 2008. 256 с.

4. Цепкова А.Н. Развитие личностного опыта ученика как идея личностно ориентированного образования // Поволжский педагогический вестник. 2016. № 1 (10). С. 28-32.

5. Фромм Э. Душа человека. М.: Республика, 1992. $429 \mathrm{c}$.

6. Эльконин Д.Б. Кризис детства и основание проектирования форм детского развития // Вопросы психологии. 1992. № 3-4. С. 7-13.

7. Сериков В.В. Личностно развивающая функция непрерывного образования // Непрерывное образование: XXI век. 2013. Т. 1, № 1 (1). С. 29-39.

8. Сериков В.В. Личностно развивающее образование как одна из культурологических образовательных моделей // Известия Волгоградского государственного педагогического университета. 2016. № 2 (106). С. 30-35.

9. Сериков В.В. Личностно развивающее образование: два десятилетия исканий // Известия Волгоградского государственного педагогического университета. 2011. № 8 (62). С. 14-20.

10. Сериков В.В. Развитие личности в образовательном процессе: монография. М.: Логос, 2012. $448 \mathrm{c}$.

11. Якиманская И.С. Концепция личностно ориентированного образования // Ученые записки Петрозаводского государственного университета. Серия: общественные и гуманитарные науки. 2010. № 5. С. $36-40$.

12. Якиманская И.С. Основы личностно ориентированного образования: монография. М.: БИНОМ. Лаборатория знаний, 2013. 222 с.

13. Якиманская И.С. Технология личностно ориентированного образования. М.: Сентябрь, 2000. 176 с. 
14. Бондаревская Е.В. Ценностные основания личностно ориентированного воспитания // Педагогика. 2007. № 8. C. 44-53.

15. Плигин А.А. Личностно ориентированное образование: история и практика: монография. М.: КСП+, 2003. $432 \mathrm{c}$.

16. Плигин А.А. От индивидуализации обучения к личностно ориентированному образованию // Психология обучения. 2009. № 2. С. 20-30.

17. Лукьянова М.И. Личностно ориентированное образование и готовность к нему педагога // Школьные технологии. 2013. № 1. С. 69-75.

18. Смолеусова Т.В. Концепция личностно ориентированного подхода в образовании на основе проявления личности // Вестник Новосибирского государственного педагогического университета. 2016. № 6 (34). C. 7-16.

19. Трубина Г.Ф. Современные концепции личностно ориентированного образования // Педагогическое образование в России. 2014. № 9. С. 165-169.

20. Разин А.В. Этика: учебник для вузов. М.: Академический проект, 2003. 624 c.

21. Титаренко А.И. Сущность, структура и функции морали // Марксистская этика. М.: Политиздат, 1980. C. $96-133$.

22. Дробницкий О.Г. Проблемы нравственности. М.: Наука, 1977. 334 с.

23. Позднякова О.К. Нравственное сознание учителя: структура и особенности // Инновационное развитие профессионального образования. 2012. № 1 (01). C. $160-166$.

\section{DEVELOPMENT OF PERSONAL FORMS OF STUDENTS' MORAL CONSCIOUSNESS AS AN IDEA OF PERSONALLY ORIENTED EDUCATION}

(C) 2017

Tsepkova Anzhelika Nicolaevna, candidate of pedagogical sciences, associate professor of Humanities and Social Sciences Department

Samara Institute - Higher School of Privatization and Entrepreneurship (Samara, Russian Federation)

Abstract. The paper justifies that a personally oriented educational model is one of the ways of solving a problem of student's personality development. The author explains the reasons for the declarative nature of personally oriented education in modern schools: classical foundations of the traditional educational paradigm, transformation of education into service and incorrect understanding of personally oriented education by teachers. The author reveals the role of future teachers' orientation on implementation of personally oriented education. The author considers development of personal forms of students' moral consciousness as an idea of personally oriented education. Special value of consciousness personal forms is proved. The author shows that specific personal forms of teachers' moral consciousness can be presented as personal forms of students' moral consciousness. The paper contains the essence of personal forms of students' moral consciousness. Such personal forms of moral consciousness as kindness, dignity, mercy, responsibility, etc. are necessary for a student to build value judgments as well as for assessment which is the starting point for the spiritual and practical mastering of the world.

Keywords: student; teacher; prospective teacher; personality; personally oriented education; idea; personal form; moral consciousness; evaluation; development; essence; spiritual mastery of world by schoolchild in morality; moral requirement.

\section{АЛГОРИТМ УПРАВЛЕНИЯ \\ ОЗДОРОВИТЕЛЬНО-КОРРИГИРУЮЩЕЙ ДЕЯТЕЛЬНОСТЬЮ ПЕДАГОГОВ В СВЯЗИ С УЧЕБНОЙ РАБОТОЙ ОБУЧАЮЩИХСЯ С КОМПЬЮТЕРОМ}

(C) 2017

Щербакова Наталья Борисовна, старший преподаватель центра дистанционного обучения Нижегородский институт развития образования (2. Нижний Новгород, Российская Федераџия)

Аннотация. Автор статьи актуализирует внимание на проблеме безопасного использования компьютера обучающимися. Отмечено, что взаимодействие школьников с компьютером сопряжено, в первую очередь, с воздействием на их здоровье таких негативных факторов, как зрительное, психическое и физическое напряжения, связанные с длительным статическим напряжением мышц пользователя персонального компьютера. В связи с этим особое значение приобретает повышение готовности педагогов к оздоровительно-корригирующей деятельности при организации работы обучающихся с компьютером. Автор выделяет следующие компоненты оздоровительно-корригирующей деятельности педагога: субъект, объект, средства, процесс, результат, среда, условия. Сформулировано базовое определение управления оздоровительно-корригирующей деятельностью педагогов. Представлен алгоритм управления здоровьеобеспечивающей деятельностью педагогов, этапы которой определены в соответствии со следующими функциями управления: проектированием, включающим в себя распределение целей и средств в пространстве (последовательность) и времени (продолжительность); организацией, представляющей собой упорядочение действий в пространстве и времени; регулированием как субординацией, координацией и коррекцией действий; контролем и учетом, суть которых состоит в сличении цели и результата, а также в фиксации и определении меры в пространстве и времени.

Ключевые слова: здоровье обучающихся; деятельность здоровьеобеспечения; готовность педагогов к оздоровительно-корригирующей деятельности в связи с учебной работой обучающихся с компьютером; алгоритм управления оздоровительно-корригирующей деятельностью педагогов в связи с учебной работой обучающихся с компьютером. 